\title{
SUCCESSFUL USE OF C1 ESTERASE INHIBITOR PROTEN IN A PATIENT WITH HEREDITARY ANGIONEUROTIC EDEMA REQUIRING CORONARY ARTERY BYPASS SURGERY
}

John M. Alvarez, FRACS, Clayton, Victoria, Australia

Hereditary angioneurotic edema (HANE) is an inherited deficiency of an inhibitor protein $(\mathrm{C} 1 \mathrm{INH})$ that inactivates the activated first component $(\mathrm{C} 1)$ of the classical complement pathway. With deficiency of C1INH, there is an unimpeded action of activated $\mathrm{C} 1$ producing a depletion of the complement proteins and concurrent accumulation of their breakdown products. The result can be a marked increase in vascular permeability and a coagulopathy. ${ }^{1}$ HANE is characterized by episodic attacks with reported mortality rates of $15 \%$ to $33 \%$; surgery is a recognized trigger. ${ }^{1}$ This report is the first to document the use of $\mathrm{C} 1 \mathrm{INH}$ concentrate (C1INH Inhibitor TIM3, Baxter Healthcare Corp, Edwards Division, Deerfield, Ill) with cardiopulmonary bypass (CPB).

From the Department of Surgery, Heart \& Chest Research Centre, Monash University, Clayton, Victoria, Australia.

Received for publication July 21, 1999; accepted for publication Sept 20, 1999.

Address for reprints: John M. Alvarez, Department of Cardiothoracic Surgery, Monash Medical Centre, 246 Clayton Rd, Clayton, Victoria 3168, Australia.

J Thorac Cardiovasc Surg 2000;119:168-71

Copyright (C) 2000 by Mosby, Inc.

$0022-5223 / 2000 \$ 12.00+0 \quad \mathbf{1 2 / 5 4 / 1 0 3 1 4 6}$
Clinical summary. A 53-year-old white man (height 169 $\mathrm{cm}$, weight $70 \mathrm{~kg}$ ) with triple vessel disease, a left ventricular ejection fraction of $30 \%$, and unstable angina was referred for urgent coronary artery bypass grafting (CABG). A 20year history of HANE with episodic life-threatening facial and limb edema had been successfully controlled for only the previous 7 years with danazol (Danacrine, Sanofi Winthrop), $200 \mathrm{mg}$ daily. Preoperatively, total (C1INH-1) and functional (C1INH-F) serum C1INH concentrations were $0.11 \mathrm{mg} / \mathrm{dL}$ (normal range $0.19-0.43 \mathrm{mg} / \mathrm{dL}$ ) and $0.28 \mathrm{U} / \mathrm{mL}$ (normal range $0.8-1.2 \mathrm{mg} / \mathrm{dL}$ ), respectively (Figs $1 \mathrm{~A}$ and $1 \mathrm{~B}$ ).

Sixty minutes before anesthetic induction, 1000 units of intravenous C1INH was given. CABG was performed with $\mathrm{CPB}$, hypothermia to $32^{\circ} \mathrm{C}$, and with antegrade and retrograde blood cardioplegia. The left internal thoracic artery was grafted to the left anterior descending coronary artery, and 2 saphenous vein grafts were anastomosed to the circumflex and right coronary arteries (aortic crossclamp time $31 \mathrm{~min}$ utes, CPB time 51 minutes).

The patient was extubated 8 hours after an uneventful operation. One hour before extubation, 1000 units of intravenous C1INH was given to minimize the potential for laryngeal edema from endotracheal intubation. No evidence of a bleed- 
Volume 119, Number 1

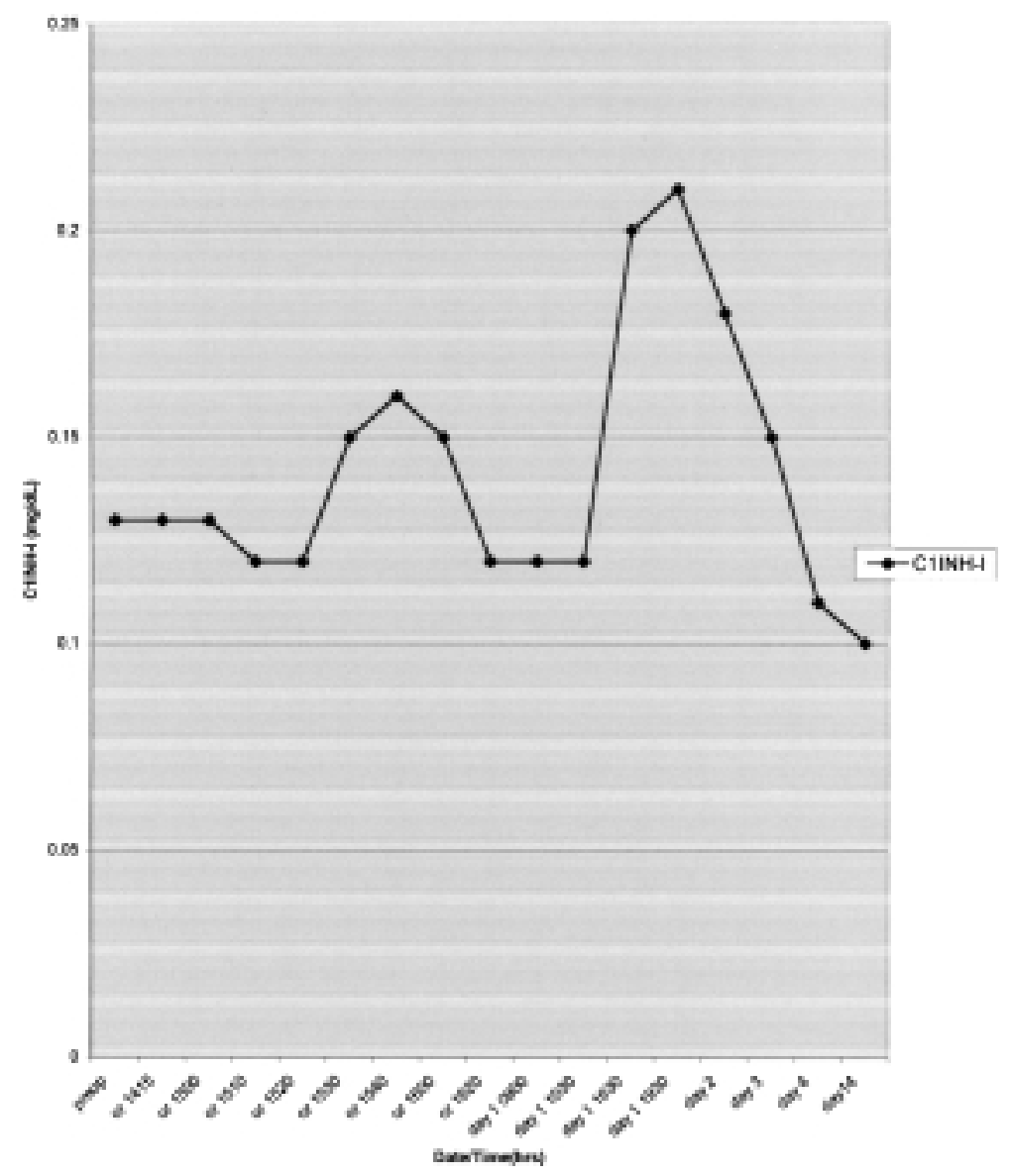

Fig 1A. Total (C1INH-I) serum C1INH levels at the following measurement times: Preop, baseline; or 1415, before heparinization; or 1500, before $\mathrm{CPB}$; or 1510, +10 minutes of $\mathrm{CPB}$; or 1520, +20 minutes of $\mathrm{CPB}$; or 1530, +30 minutes of CPB; or 1540, +40 minutes of CPB; or 1600, after CPB; or 1620, after total protamine dose; day 1, 0900, before extubation; day 1, 1030, +90 minutes after extubation; day 1, 1630, +7.5 hours after extubation; day 1, 1930, +12.5 hours after extubation.

ing diathesis or significant limb, face, or neck edema occurred, and he was discharged to his home 6 days later.

Discussion. HANE is an autosomal dominant disease with 2 variants: $85 \%$ of patients have a deficiency of $\mathrm{C} 1 \mathrm{INH}$ and $15 \%$ of patients have normal serum levels but functionally inactive C1INH. The majority of patients do not require longterm drug treatment. Androgen therapy, which increases hepatic synthesis of $\mathrm{C} 1 \mathrm{INH}$, is recommended for frequent or life-threatening attacks. ${ }^{1}$

Optimal perioperative management for HANE is unclear. Continuation of and/or several days of increased androgen before the operation, 2 units of fresh-frozen plasma 24 hours before the operation, and/or a short course of antifibrinolytic therapy have been recommended. ${ }^{1,4}$ Ostensibly, outcome will be determined by the interaction between the magnitude of the stressor (surgery) and the serum level of $\mathrm{C} 1 \mathrm{INH}-\mathrm{I} / \mathrm{F}$. Records of $\mathrm{C} 1 \mathrm{INH}-\mathrm{I} / \mathrm{F}$ in reported cases are scarce. Hence such recommendations must be viewed with caution. ${ }^{3}$ Importantly, no effective therapy exists for acute attacks. $^{3}$

CPB is particularly challenging to these patients. First, the hemodilution associated with $\mathrm{CPB}$ is known to reduce serum C1INH levels by $30 \%$ to $50 \% .^{3}$ Second, complement activation occurs during $\mathrm{CPB}$ and with the administration of protamine. Furthermore, a safe lower level of C1INH is unknown. ${ }^{1,3}$ Therefore these patients may have uncontrolled complement activation.

Only 3 case histories of patients with HANE requiring CPB have been reported. ${ }^{2,3}$ One patient, a child with only biochemical evidence of HANE, had successful closure of an atrial septal defect. ${ }^{3}$ Haering and Comunale ${ }^{3}$ reported on a 71-year-old man receiving long-term stanozolol therapy who had an uncomplicated CABG. The dose of stanozolol was doubled for 5 days before the operation. This patient's baseline serum C1INH level was $0.11 \mathrm{mg} / \mathrm{dL}$ ( $75 \%$ of normal). No increase in C1INH was evident after 5 days of increased 


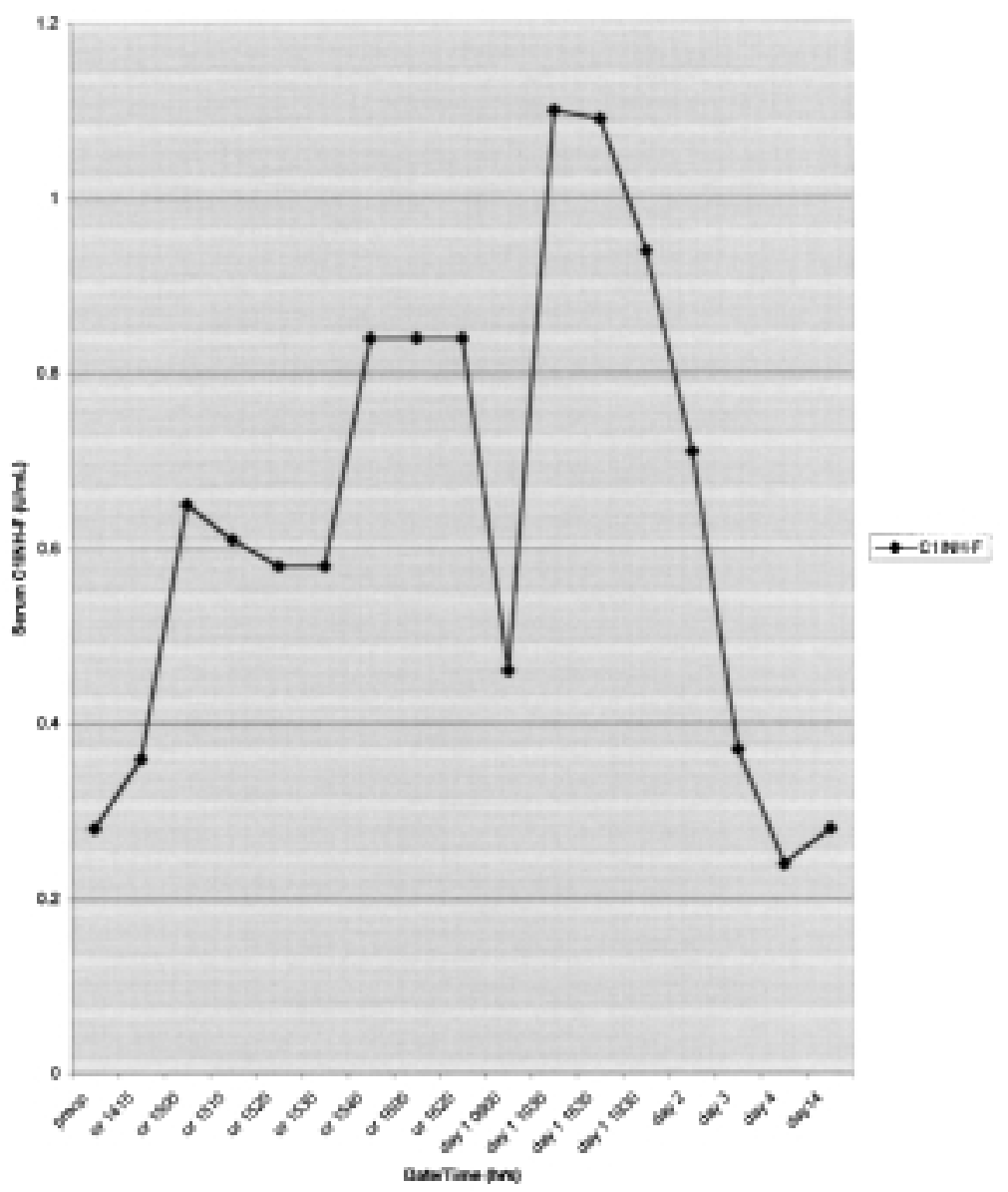

Fig 1B. Functional C1INH-F serum C1INH levels. For legend, see Fig 1A.

androgen therapy. During CPB, serum C1INH concentration fell to a nadir of $0.6 \mathrm{mg} / \mathrm{dL}$ ( $38 \%$ of normal) after protamine administration.

Bonser and coworkers ${ }^{2}$ reported on a 74-year-old patient requiring $\mathrm{CABG}$ who was on a program of long-term danazol therapy (200 $\mathrm{mg}$ daily) and received the drug until the day of the operation. Disseminated coagulopathy with generalized systemic and pulmonary edema immediately after CPB proved fatal. This patient's baseline C1INH level was $0.6 \mathrm{mg} / \mathrm{dL}$ ( $38 \%$ of normal). Bonser and colleagues ${ }^{2}$ believed that a maintenance dose of androgen therapy was inadequate and suggested that higher doses should be administered for at least 1 week before the operation in the expectation that $\mathrm{C} 1 \mathrm{INH}$ levels can be increased to greater than $50 \%$ of normal. They concluded that CPB in patients with C1INH deficiency is extremely hazardous. Neither Bonser's group ${ }^{2}$ nor Haering and Comunale $^{3}$ measured serum C1INH-F.

Our patient continued to receive androgen therapy until the time of the operation. We have demonstrated that 1000 plasma units of $\mathrm{C} 1 \mathrm{INH}$ maintained the level of $\mathrm{C} 11 \mathrm{NH}$ during $\mathrm{CPB}$. There was no significant reduction in either total or functionally active serum C1INH (Figs 1A and 1B) during 60 minutes of $\mathrm{CPB}$. The further administration of 1000 units of $\mathrm{C} 1 \mathrm{INH}$ before extubation doubled and maintained the serum C1INH-I/F for 48 hours. The half-life of C1INH is 18 hours (product information, Baxter Edwards Laboratories).

Therefore, depending on the baseline level, CPB can reduce the serum $\mathrm{C} 1 \mathrm{INH}$ concentration, with fatal consequences. Hence measurement of preoperative serum C1INH$\mathrm{I} / \mathrm{F}$ is important. In conclusion, the prophylactic use of $\mathrm{C} 1 \mathrm{INH}$ concentrate in patients with HANE requiring $\mathrm{CPB}$ prevents serum $\mathrm{C} 1 \mathrm{INH}-\mathrm{I} / \mathrm{F}$ levels from decreasing. Uncontrolled complement activation is prevented and potentially fatal complications are thereby avoided. Given that a safe lower limit of C1INH is not known and conventional therapy for acute attacks is ineffective, the prophylactic use of C1INH concentrate is recommended.

\section{REFERENCES}

1. Gadek JE, Hosea SW, Gelfand JA, Santaella M, Wickerhauser M, Triantaphyllopoulos DC, Frank MM. Replacement therapy in hereditary angioedema: successful treatment of acute episodes of 
angioedema with partly purified $\mathrm{C} 1$ inhibitor. N Engl $\mathrm{J}$ Med 1980:302:542-46.

2. Bonser RS, Dave J, Morgan J, Morgan C, Davies E, Taylor P, et al. Complement activation during bypass in acquired $\mathrm{C} 1$ esterase inhibitor deficiency. Ann Thorac Surg 1991;52;541-3.
3. Haering JM, Comunale ME. Cardiopulmonary bypass in hereditary angioedema. Anesthesiology 1993;79:1429-33.

4. Wall R, Frank M, Hahn M. A review of 25 patients with hereditary angioedema requiring surgery. Anaesthesiology 1989;71: 309-11. 